\title{
Verification of Response of Neutron Monitor for In-Flight Neutron Dosimetry
}

\author{
Claudio Antonio Federico ${ }^{1}$ Odair Lélis Gonçalez ${ }^{1}$, Evaldo Simões da Fonseca², Karla Cristina de Souza \\ Patrão², Marlon Antonio Pereira' ${ }^{1}$ Linda Viola Ehlin Caldas ${ }^{3}$
}

\begin{abstract}
In this work, we present the results of verification of special neutron monitoring equipment for use in aircrew dosimetry inside aircraft. The equipment was precalibrated with conventional neutron sources in a National Standard Laboratory of the Institute for Radioprotection and Dosimetry (IRD, Brazil) and verified in a Cosmic Energy Reference Field (CERF), a special field from CERN (Centre Européan de Recherche Nucléaire), a facility that reproduces the shape of neutron field encountered in the atmosphere at aircraft altitudes. The equipment consists of a special neutron probe from Thermo Scientific with response up to $5 \mathrm{GeV}$ neutrons and was verified with respect to ambient dose equivalent rate linearity and angular incidence. The results show the adequacy of the equipment for this type of measurement and the feasibility to use conventional neutron sources to calibrate this specific equipment, in the absence of access to the CERF field.
\end{abstract}

KEYWORDS: Radiation dose, Aircrew, Neutron dose.

\section{INTRODUCTION}

In recent decades, the problem of controlling the level of ionizing radiation dose received by aircrew and sensitive equipment has received great attention and motivated several studies in specialized international literature (FAA, 1990; Wilson et al., 1998; Bartlett, 2004; Edwards et al., 2004; Hajek et al., 2004). In Brazil, these studies were initiated by the Brazilian Air Force (FAB) in conjunction with research institutions from the National Commission on Nuclear Energy (CNEN) (Federico et al., 2010a, 2010b, 2012).

The reason for this concern is the fact that the dose rate arising from cosmic radiation (CR) undergoes a considerable increase with altitude, and consequently, aircrew frequently exceed the annual effective dose limit proposed by international organizations for planned exposures to members of the public (ICRP, 1991), which is $1 \mathrm{mSv}$.

The International Commission on Radiological Protection (ICRP) recognizes the need to control exposure for the group of professional flight crew and pilots (ICRP, 1998) because this group is exposed to radiation levels that are comparable with or greater than the average levels of radiation received by professionals working with radiation in medicine and technology.

The measurement quantity recommended for aircraft is the ambient dose equivalent $\left(H^{*}(10)\right)$, and its employment for purposes of dosimetric control is made by conversion factors for effective dose recommended in the literature, so that the results obtained through the calibrated equipment

\footnotetext{
1.Instituto de Esudos Avançados - São José dos Campos/SP - Brazil 2.Instituto de Radioproteção e Dosimetria - Rio de Janeiro/RJ - Brazil 3.Instituto de Pesquisas Energéticas e Nucleares - São Paulo/SP - Brazil 
can be compared to the limits applicable to the crew of the aircraft.

Due to the large contribution of the neutron component in ambient dose equivalent incident in aircrews and in singleevent effects in aircraft avionics, it is necessary to calibrate the response of the instrumentation used in relation to the field of neutrons present at flight altitudes. This calibration is not a conventional procedure due to higher energy of the field and the lack of facilities with this capability.

The neutron radiation field produced by $\mathrm{CR}$ covers energy up to the order of hundreds of $\mathrm{MeV}$, presenting more pronounced peaks in the region of thermal neutrons (about $0.023 \mathrm{eV}$ ), neutron evaporation (about $1 \mathrm{MeV}$ ), and neutrons from spallation processes in atmospheric constituents (peak around $100 \mathrm{MeV}$ ). In special, the thermal peak is not very significant in the atmosphere, due to neutron absorption on nitrogen, but can be greatly enhanced by the presence of thermalizing materials within aircraft, such as, the fuel. The characteristics of this type of field are very different from those obtained in neutronic fields emitted by conventional sources of radionuclides, accelerators, or reactors, forcing the use of specific and characterized fields, with broad spectra, created specifically to simulate those obtained at the sites of measurement (Schuhmacher, 2004), for verification or calibration of measuring instruments.

There is a special arrangement in the laboratories of CERN (Centre Européan de Recherche Nucléaire) called CERF (CERN-EU high energy Reference Field), Prevessin, France, designed to reproduce, with reasonable proximity, the existing field on aircraft flight altitudes. While this field cannot be treated as a metrological standard, it is recognized as amongst "the best efforts" in the world to reproduce this kind of neutron field and is widely used to verify the instrumentation used for aeronautical dosimetry purposes.

\section{EXPERIMENTAL PROCEDURE}

\section{THE DETECTION SYSTEM}

The FH THERMO detection system consists of a Thermo Electron Eberline acquisition, model FH40G-10, with remote programming capability through connection to a computer, coupled to an internal proportional counter, and allows the connection of an external probe with simultaneous acquisition. The internal proportional counter gives the results from low LET components of the field, and the system was designed and calibrated to provide results directly of the operational quantity ambient dose equivalent $\left(\mathrm{H}^{\star}(10)\right)$ and can be operated directly or programmed to acquire measurements of dose rate at time intervals set by the user, which can vary from 1 second to several hours. The system has a volatile internal memory that lets you store the results of up to 256 measuring points, which can be collected by the user later. Each measurement point consists of a record, with information covering the start and finish times of each measurement interval, the result of the proportional internal probe measurement unit, the measurement result of the optional external probe, the measurement unit, the measurement interval (in seconds), and the type of external coupled probe.

For the measurements reported here, the THERMO FHT-762 (WENDI-II) was coupled to the external probe system, which consists of a ${ }^{3} \mathrm{He}$ proportional type neutron probe, covered with a layer of tungsten and an external polyethylene layer, which allows obtaining the response to neutrons with energies up to about $5 \mathrm{GeV}$, and which differs greatly from conventional neutron detectors that typically have an adequate response to energies up to at most about $20 \mathrm{MeV}$.

The efficiency curve for ambient dose equivalent as a function of neutron energy is shown in Fig. 1, compared

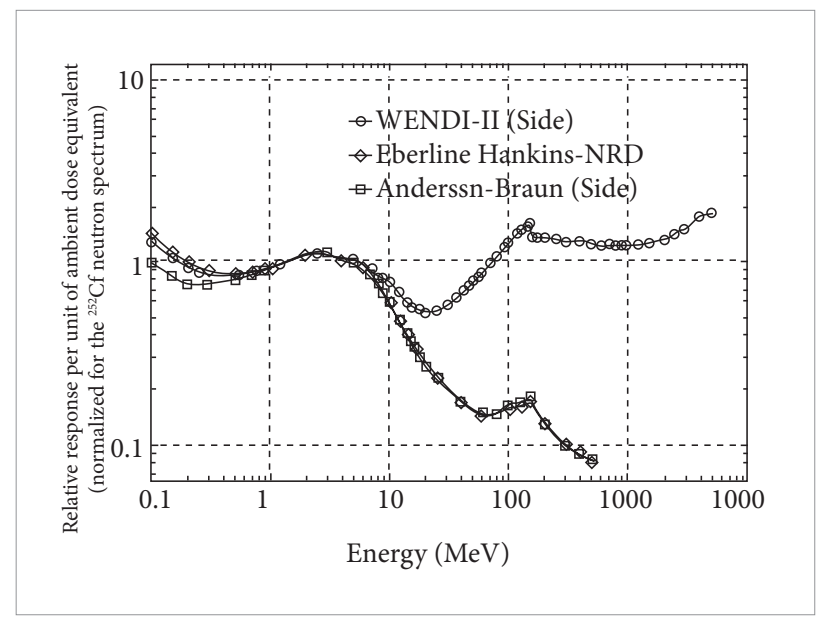

Figure 1. Response curve depending on the incident neutron energy to the probe FHT-762 (WENDI-II), compared with that obtained for other conventional monitor type Eberline Hankins-NRD and Andersson-Braun (extracted from Thermo-Scientific, 2009). 
Table 1. Main characteristics of FHT-762 probe (ThermoScientific, 2009).

\begin{tabular}{|c|c|c|}
\hline Parameters & Value & Observations \\
\hline $\begin{array}{c}\text { Measurement } \\
\text { interval }\end{array}$ & $\left(0.001\right.$ to $\left.1 \times 10^{6}\right) \mu \mathrm{Sv} / \mathrm{h}$ & \\
\hline $\begin{array}{c}\text { Sensitiveness } \\
\text { Linearity }\end{array}$ & $0.84 \mathrm{cps} /(\mu \mathrm{Sv} / \mathrm{h})$ & $\begin{array}{c}\text { Referenced to } \\
\text { neutrons of }{ }^{252} \mathrm{Cf}\end{array}$ \\
\hline $\begin{array}{c}\text { Energy } \\
\text { interval }\end{array}$ & $25 \mathrm{meV}$ to $5 \mathrm{GeV}$ & $\begin{array}{c}\text { Response curve according } \\
\text { to ICRP } 74(1997)\end{array}$ \\
$\begin{array}{c}\text { Angular } \\
\text { dependence } \\
\text { Pressure } \\
\text { interval }\end{array}$ & 500 to $1500 \mathrm{hPa}$ & \\
\hline
\end{tabular}

with the curve obtained in other conventional equipment (Thermo-Scientific, 2009). The main features of neutron measurement system are presented in Table 1 and the same is calibrated in the field relative to a neutron source from ${ }^{241} \mathrm{Am} / \mathrm{Be}$.

\section{CONVENTIONAL SOURCES}

Initially the neutron probe was recalibrated at the Neutron Laboratory of the Ionizing Radiation Metrology National Laboratory, Brazil, using standard sources of ${ }^{241} \mathrm{Am} / \mathrm{Be}$ and ${ }^{252} \mathrm{Cf}$. The traditional calibration protocol of the laboratory was modified to suit the peculiarity in the use of equipment that operates with low dose rates, present in aircraft flight altitudes. The equipment was exposed to different distances from the standard sources, ranging from about $0.86 \mathrm{~m}$ up to $4.7 \mathrm{~m}$, where the ambient dose equivalent of the neutron field is known with a combined average uncertainty varying from around 9 to $2 \%$ for sources of ${ }^{252} \mathrm{Cf}$ and ${ }^{241} \mathrm{Am} / \mathrm{Be}$ respectively. Such uncertainty is a combination average of the sources of uncertainty given in Table 2.

In the calibration process, we used a shadow cone constructed in accordance with the Safety Report Series 16 (IAEA, 2000), and for each measurement point (distance from source) calibration was performed in two stages, with and without using the shadow cone, so as to eliminate the contribution of the components originating from neutrons scattered in the environment, according to the methodology used in Federico et al., (2010a).

The quantity used for calibration was the ambient dose equivalent, whose conventional true value was obtained
Table 2. Source of uncertainties at the Neutron Laboratory setup of the lonizing Radiation Metrology National Laboratory.

\begin{tabular}{|c|c|c|}
\hline \multirow{2}{*}{ Factor } & \multicolumn{2}{|c|}{ Uncertainty [\%] } \\
\cline { 2 - 3 } & ${ }^{241} \mathrm{Am} / \mathrm{Be}$ & ${ }^{252} \mathrm{Cf}$ \\
\hline Emission rate & 1.1 & 2 \\
\hline Converting coefficient & 4 & 1 \\
\hline Time & 1 & 1 \\
\hline Scattering & 1 & 1 \\
\hline Positioning & 0.6 & 0.6 \\
\hline
\end{tabular}

from the value of the emission rate of the neutron source, determined by means of a bath of manganese sulfate. The bath of manganese sulfate, which is the primary standard for determining the rate of emission of neutron sources, is traceable to International Metrological System through the "K9" key comparison (Roberts et al., 2011), coordinated by the Bureau International des Poids et Mesures (BIPM).

\section{THE CENTRE EUROPÉAN DE RECHERCHE NUCLÉAIRE HIGH ENERGY REFERENCE FIELD}

The CERF field is produced by a hadron beam, comprising $34.8 \%$ protons, $60.7 \%$ pions, and $4.5 \%$ kaons, accelerated to an energy of $120 \mathrm{GeV}$ and incident on a copper target (Mitaroff and Silari, 2002). The acceleration of the beam until the energy extraction occurs on an acceleration ring of $6.8 \mathrm{~km}$ in circumference, having a $48 \mathrm{~s}$ cycle between each pulse of particles to be accelerated. Due to the dispersion occurred in the acceleration process, the extracted beam has an average duration of $9 \mathrm{~s}$, with the pulse shape shown in Fig. 2 for average dose rates during the pulse varying between 11 and $1300 \mu \mathrm{Sv} / \mathrm{h}$, where the intensity of the pulse can be controlled by the user from the main control room, through a set of collimators that are adjustable remotely.

Two neutron fields are available with different characteristics. The first one uses the neutrons generated on the target and passing through an iron platform according to the schematic drawing shown in Fig. 3.

The distribution of neutron fluence as a function of the energy was evaluated by Mitaroff and Silari (2002) and, for the field in iron platform, the shape of spectra extends from thermal up to $600 \mathrm{MeV}$, with the predominance of the neutron energy in the range of $0.1-1 \mathrm{MeV}$. 


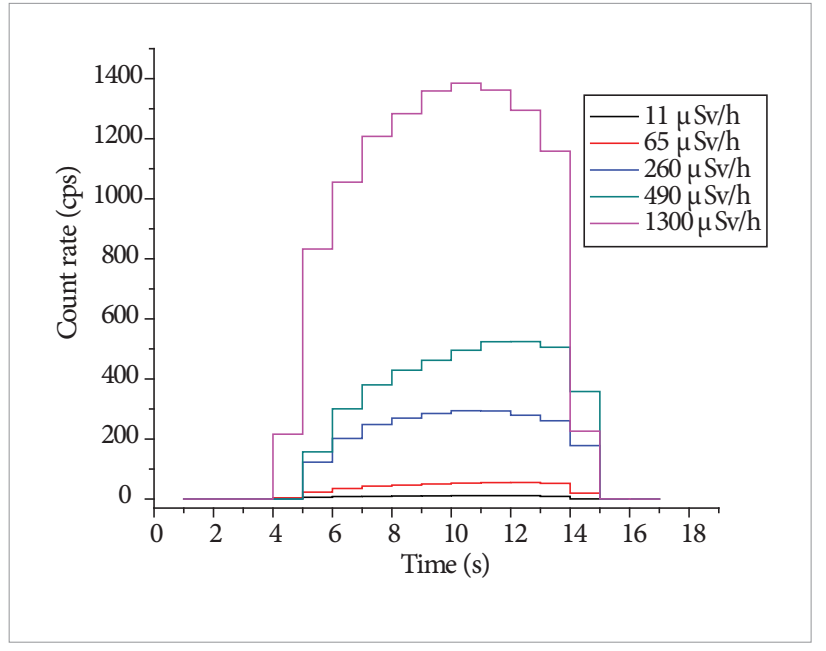

Figure 2. Hadrons pulse shape for dose rates used.

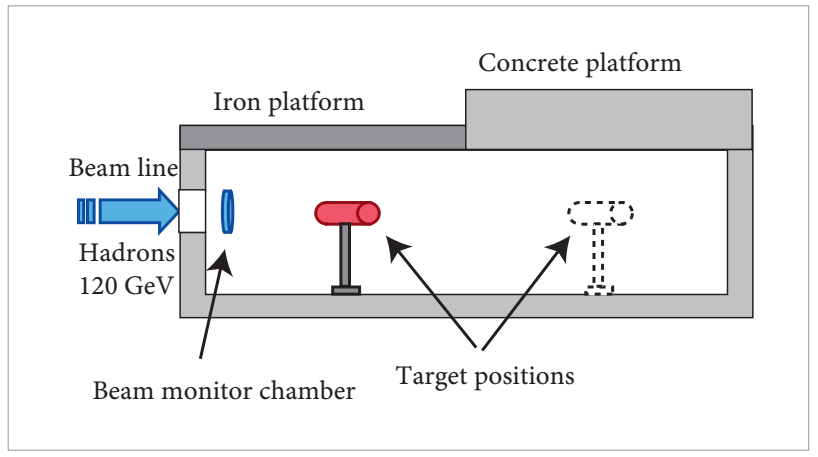

Figure 3. Schematic drawing of the layout of irradiation, with the positions of the beam, target, and measurement sites.

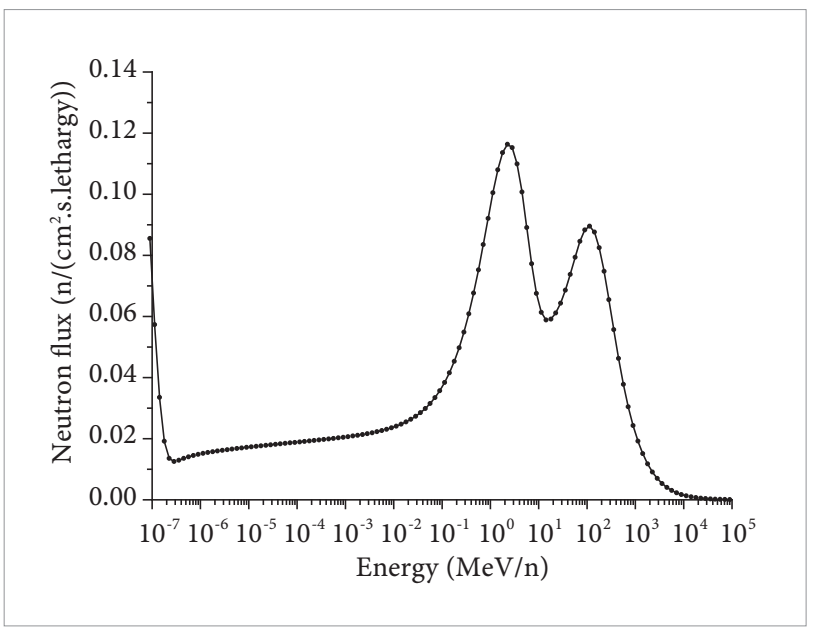

Figure 4. Typical shape of the neutron flux spectrum at $35,000 \mathrm{ft}$ altitude, made using EXPACS code (Sato and Niita, 2006).
The second field, of the most interest to this work, utilizes neutrons generated on the target and passing through a concrete platform, whose spectrum in the position above the concrete platform extends from thermal neutrons up to $500 \mathrm{MeV}$, with the presence of pronounced peaks characteristic of processes of evaporation and spallation in atomic nuclei (from 1 up to hundreds of $\mathrm{MeV}$ ) and with great similarity, in shape of the spectrum, with the typical spectrum of neutrons in aircraft flight altitudes (Fig. 4).

The detectors were irradiated at predetermined positions on the platforms of concrete and iron, where the particle flux and spectra can be calculated from the number of counts (PIC counts) obtained in one beam monitor chamber, placed at the exit of the hadrons extraction channel (Fig. 3).

\section{RESULTS}

The results of measurements with the source ${ }^{241} \mathrm{Am} / \mathrm{Be}$ and ${ }^{252} \mathrm{Cf}$ are shown in Figs. 5 and 6 respectively, along with the lines resulting from a linear fit to experimental data, where the uncertainties in the measurements and in the conventional true value were considered as weight factor in the fitting process. The conventional true value is the best estimative of the true value of the quantity, given by the laboratory maintainer, based on metrological references, as explained previously.

During the verification process of the response of the instrument in the CERF, it was observed that the

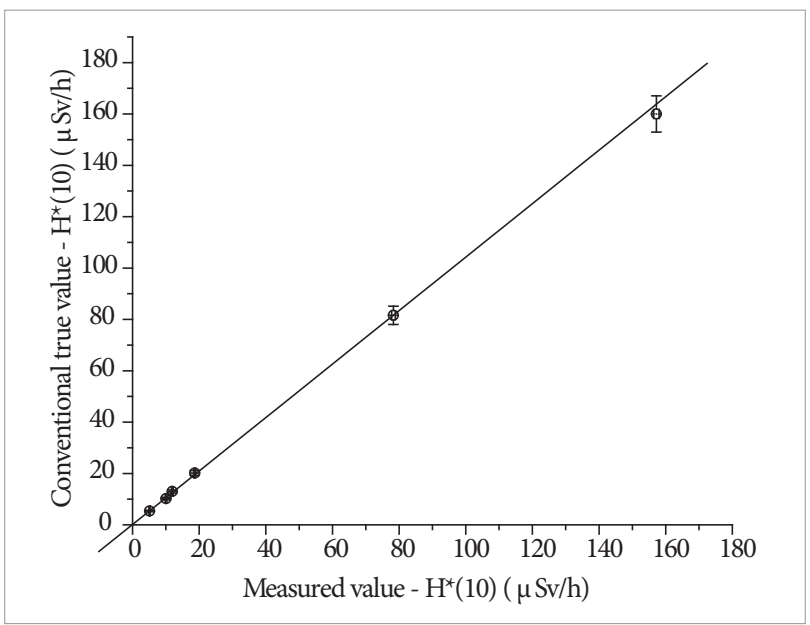

Figure 5. Measurements obtained with the ${ }^{241} \mathrm{Am} / \mathrm{Be}$ source, with straight line fitted to experimental data. 
background(BG)radiationintheplaceisvariableanddepends, among other factors, on the opening of collimators which are used to control the rate of the desired dose. Through the FH40G-10 detector and its neutron probe, we obtained the BG neutron field in some configurations and an empiric

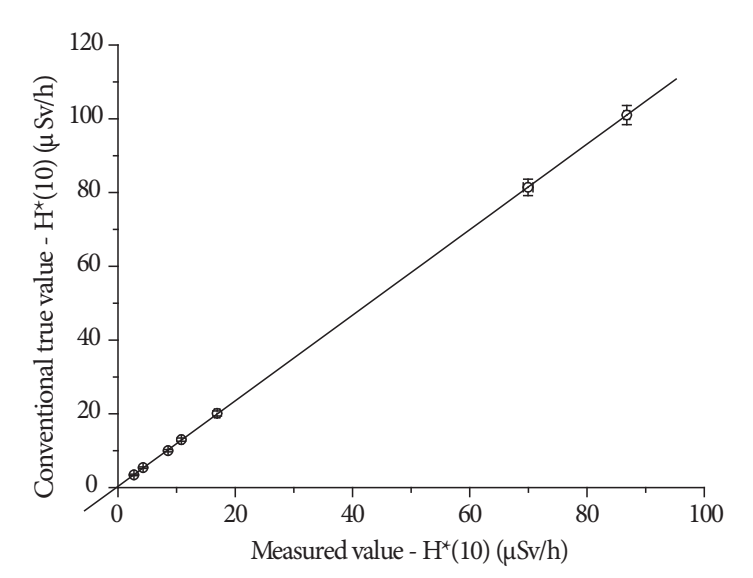

Figure 6. Measurements obtained with the ${ }^{252} \mathrm{Cf}$ source, with straight line fitted to experimental data.

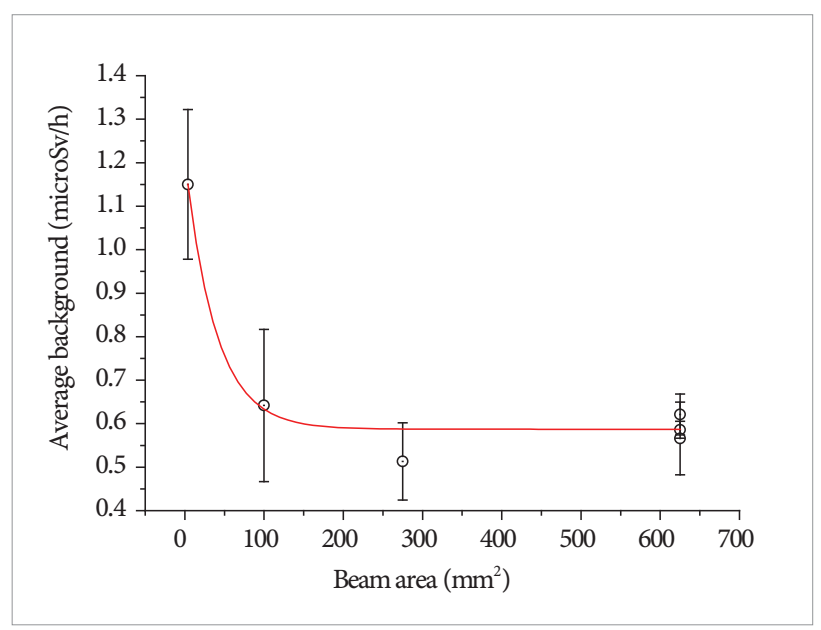

Figure 7. Evaluation of the background component in the neutron field Centre European de Recherche Nucleaire high energy Reference Field.

Table 3. Empirical function and coefficients from background adjust.

\begin{tabular}{|c|c|c|}
\hline \multirow{2}{*}{ Function type } & \multicolumn{2}{|c|}{$\mathrm{Y}=\mathrm{A} 1 * \exp [-\mathrm{x} / \mathrm{A} 2]+\mathrm{A} 3$} \\
\hline Parameters & Value & Uncertainty \\
\hline A1 & 0.62 & 0.22 \\
A2 & 38 & 58 \\
\hline A3 & 0.587 & 0.017 \\
\hline
\end{tabular}

function was adjusted to express the BG to be subtracted from experimental measurements, as a function of the opening of collimators for each measurement, as can be seen in Fig. 7. The function type and the coefficients obtained are presented in Table 3.

The verification of the response of the detector FH40G-10 with the neutron probe (FHT-762) was made by means of comparison with the conventional values of the ambient dose equivalent of the neutron field, for the CERF fields from concrete and iron platforms. The results are shown in Figs. 8 and 9, in which it can

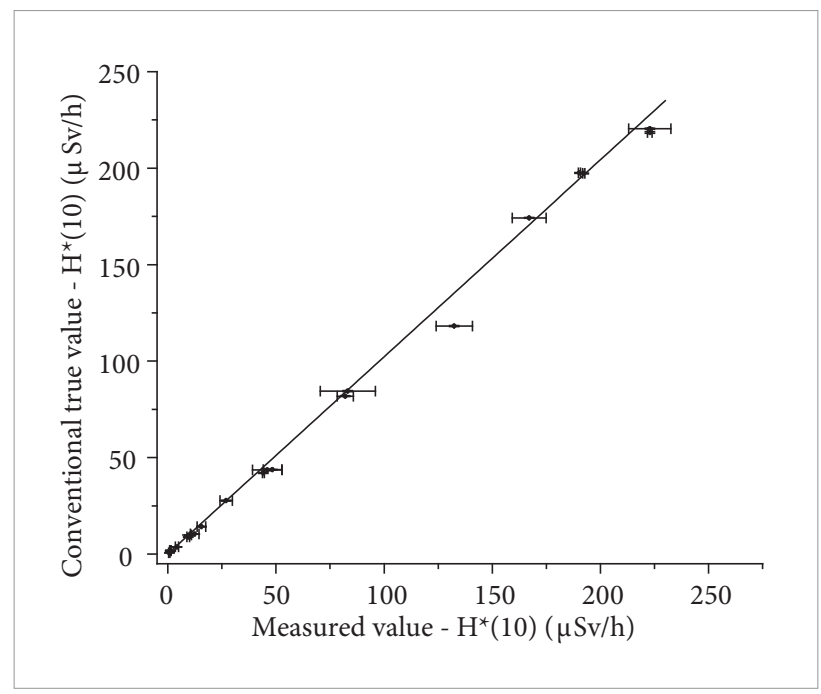

Figure 8. Response curve as a function of dose rate for the probe FHT 762, in the field of concrete, with straight line fitted to experimental data.

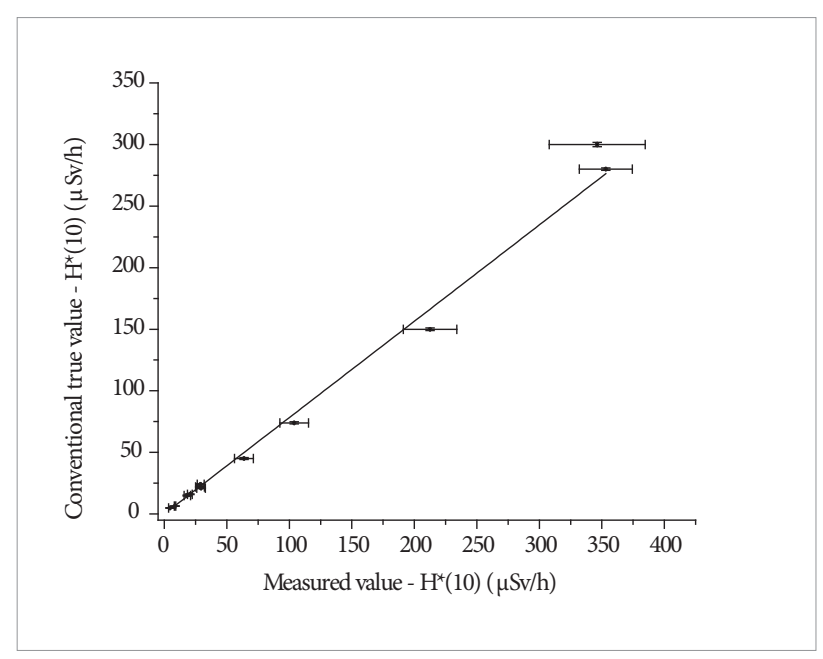

Figure 9. Response curve as a function of the dose rate for the FHT 762 probe, in the field of iron, with straight line fitted to experimental data. 
also be observed the lines resulting from linear fittings to the experimental data, where the uncertainties in the measurements were considered as weighting factors in the fitting process. The conventional value of the ambient dose equivalent was previously obtained by Mitaroff and Silari (2002).

Table 4 presents the coefficients obtained for each linear fitting performed by the least squares method, where one can observe that the value of the constant term for the four-neutron radiation fields used are compatible to zero, with a confidence interval of up to two standard deviations. It is observed in the same table an underestimation of $4 \%$ on the value indicated by the instrument for ${ }^{241} \mathrm{Am} / \mathrm{Be}$ neutron field and $16 \%$ for the ${ }^{252} \mathrm{Cf}$ neutron field. This underestimation of the real value can be explained by the dependence of the response to the energy of the neutrons reported by the equipment manufacturer, considering that the average energy of the ${ }^{241} \mathrm{Am} / \mathrm{Be}$ neutrons is approximately $4.5 \mathrm{MeV}$ and the ${ }^{252} \mathrm{Cf}$ ones approximately $1 \mathrm{MeV}$.

We can suppose that, for a good calibration, the relation between the measured values and the reference values is linear, without any constant off-set. Indeed, for the CERF field in concrete platform, which is of particular interest in this work, the constant coefficient obtained in the fitting is compatible to zero, which indicate that there is no systematic deviation of the measured values in relation to the reference values of neutron field. Therefore, a new fitting assuming the constant coefficient as null was accomplished. The uncertainty $\sigma_{\mathrm{A}}$ obtained previously is now encompassed in the uncertainty of the calibration factor (angular coefficient). This new fitting obtains the value of $1.022 \pm 0.005$ for the slope, with an adjusted R-square equal to 0.998 , which indicates that the instrument readings should be corrected by $+2.2 \%$ with a statistical uncertainty in coefficient of $0.5 \%$.

Table 4. Results from the linear fitting to the experimental data.

\begin{tabular}{|c|c|c|c|c|}
\hline \multirow{2}{*}{ Source } & \multicolumn{2}{|c|}{$\begin{array}{c}\text { Constant } \\
\text { coefficient }\end{array}$} & \multicolumn{2}{c|}{ Angular coefficient } \\
\cline { 2 - 5 } & A & $\sigma_{\text {A }}$ & B & $\sigma_{\mathbf{B}}$ \\
\hline${ }^{241} \mathrm{Am} / \mathrm{Be}$ & 0.14 & 0.25 & 1.040 & 0.020 \\
\hline${ }^{252} \mathrm{Cf}$ & 0.33 & 0.21 & 1.160 & 0.022 \\
\hline $\mathrm{CERF}$ (iron) & 0.05 & 0.91 & 0.782 & 0.018 \\
\hline $\mathrm{CERF}$ (concrete) & 0.12 & 0.39 & 1.021 & 0.006 \\
\hline
\end{tabular}

This uncertainty, obtained from the linear fitting of the instrument readings on CERN standard field values, is of statistical nature because it is only associated with the instrument reading errors. But, Mitaroff and Silari (2002) reported an uncertainty of $2 \%$ in the value of the standard field used in this calibration that affects in the same way all calibration data. Therefore, wemust considerthisasasystematic error of statistical nature in the calibration procedure, which could be taken into account as a covariance. Considering that the calibration function is linear and that we considered only the variations of statistical nature in obtaining the calibration coefficient by the linear fitting, the uncertainty of the field must be quadratically added to the uncertainty of the calibration coefficient value in order to calculate the standard deviation of the calibration coefficient. Thus, the calibration coefficient for the THERMO FH detector system for the neutron component is $1.022 \pm 0.021$.

We also evaluated the dependence of the response with the orientation of the detector positioning on the concrete platform of the CERF field, using the positions of standing, lying, and upside down, where differences below $1 \%$ were observed for the equipment in question, as can be seen in Fig. 10. We may therefore disregard the influences of the positioning direction.

Comparing the results obtained in this study with measurements made by Mayer et al., (2007) for this same type of equipment, it is observed that the author noticed a difference of $-11.9 \%$ in the response of the detector to the

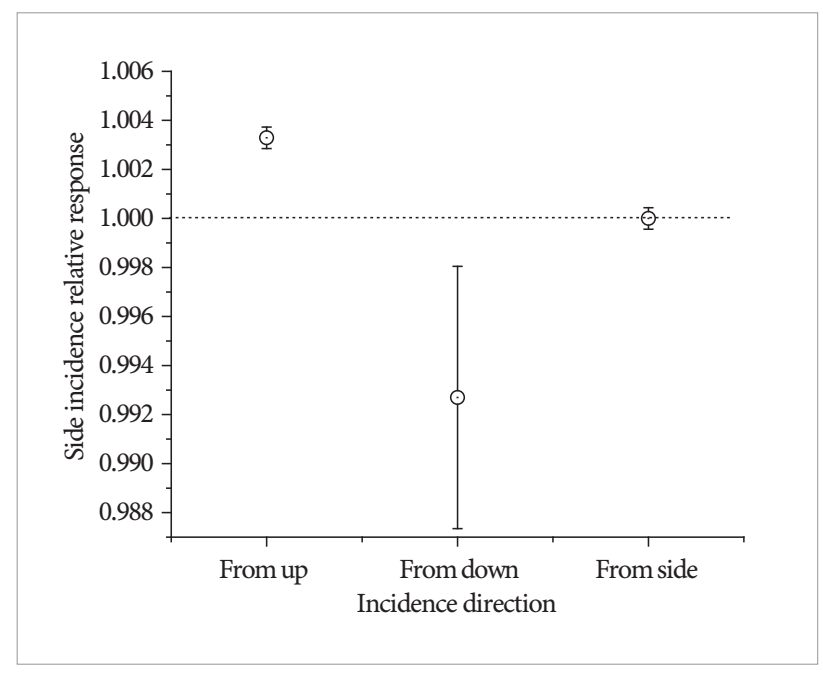

Figure 10. Response curve as a function of preferential direction of incidence for FHT 762 probe. 
field in the CERF concrete platform regarding calibration performed for the field of ${ }^{252} \mathrm{Cf}$. In this study, the difference between the response of the CERF field in concrete platform in relation to the response obtained for the field of ${ }^{252} \mathrm{Cf}$ is about $13.9 \%$, with an uncertainty of about $2.2 \%$, confirming the result obtained by Mayer et al., (2007) within one standard deviation.

Similarly, Yasuda and Yajima (2010) made tests with the same type of monitor, calibrated for neutron from ${ }^{241} \mathrm{Am} / \mathrm{Be}$ sources and found differences in the $\mathrm{H}^{*}(10)$ rate measured in relation to the $H^{\star}(10)$ calculated rate of about $3 \%$, consistent with the underestimation of $2.2 \%$, with an uncertainty of about $2.1 \%$, found in this study.

\section{CONCLUSION}

The results in terms of rate of environment equivalent dose indicate that the detector responds appropriately to high-energy neutrons, which can be used for radiation measurements on aircraft, with a small correction in the value read from the instrument. By the results obtained in this work and by Yasuda and Yajima (2010), one can observe that the difference between the response of $\mathrm{H}^{*}(10)$ of such equipment to the $\mathrm{CR}$ field and the response calibrated to conventional sources of ${ }^{241} \mathrm{Am} / \mathrm{Be}$ is about -2 to $-3 \%$, and this type of source can be used for calibration of this instrument, in the case of inability to use the CERF field. This is a very important result due to the difficulties related on support for this type of calibration in CERF field, especially for people from outside of Europe.

Unfortunately, Mayer et al., (2007) show that the same is not the case for other types of conventional neutron detectors whose responses are hardly suitable for energy greater than $16 \mathrm{MeV}$, being therefore, for the most part, unsuitable for $\mathrm{H}^{*}(10)$ measurements of neutrons from CR.

The characterization of this equipment to the field of $\mathrm{CR}$ at aircraft flight altitude is an important step in the consolidation of a Brazilian group with training, experience, and proper equipment to perform such measurements in flight, which does not currently exist in Brazil, nor possibly elsewhere in Latin America.

\section{ACKNOWLEDGMENTS}

We thank FINEP and CNPQ for partial financial support; to CERN, for allowing the verification of instruments in the CERF field; and to the Brazilian Air Force, which supports this research in IEAv.

\section{REFERENCES}

Bartlett, D.T., 2004, "Radiation protection aspects of the cosmic radiation exposure of aircraft crew", Radiation Protection Dosimetry, Vol. 109, No. 4, pp. 349-355.

Edwards, R.E., Normand, E., Dyer, C.S., 2004, "Technical Standards for atmospheric radiation single event effects [SEE] on avionics electronics", IEEE Radiation effects Data Workshop Record, IEEE 04TH8774, 2004.

FAA, 1990, Federal Aviation Administration, U.S. Department of Transportation, Radiation Exposure of Air Carrier Crewmembers. FAA Advisory Circular n. 120-152.

Federico, C.A., Gonçalez, O.L., Fonseca, E.S., Martin, I.M. and Caldas, L.V.E, 2010a, "Neutron Spectra Measurements in the South Atlantic Anomaly Region”, Radiation Measurements, Vol. 45, No. 10, pp.1526-1528.

Federico, C.A., Pereira, H.H.C., Pereira, M.A., Gonçalez, O.L. and Caldas, L.V.E., 2010 b, "Estimates of Cosmic Radiation Dose Received
By Aircrew of DCTA's Flight Test Special Group", Journal of Aerospace Technology and Management, Vol. 2, pp. 137-144.

Federico, C.A., Gonçalez, O.L., Sordi, G.M.A.A. and Caldas, L.V.E., 2012, "Effects of Cosmic Radiation in Aircrafts: A Discussion about Aircrew over South America", Journal of Aerospace Technology and Management, São José dos Campos, Vol. 4, No. 2, pp. 219-225, Apr-Jun.

Hajek, M., Berger, T. and Vana, N., 2004, "A TLD-based personal dosemeter system for aircrew monitoring", Radiation Protection Dosimetry, Vol. 110, No. 1-4, pp. 337-341.

IAEA, 2000, Calibration of Radiation Protection Monitoring Instruments, Safety Report Series 16, International Atomic Energy Agency, Vienna.

ICRP, 1991, International Commission on Radiological Protection. Recommendations of the international commission on radiological protection, Publication 60, Annals of the ICRP, Vol. 21, No. 1-3. 
ICRP, 1997, International Commission on Radiological Protection. Conversion coefficients for use in radiological protection against external radiation, Publication 74, Annals of the ICRP, Vol. 26, No. 3.

ICRP, 1998, International Commission on Radiological Protection. General principles for the radiation protection of workers, Publication 75, Annals of the ICRP, Vol. 27, No. 1.

Mayer, S., Forkel-Wirth, D., Fuerstner, M., Menzel, H.G., Mueller, M.J., Perrin, D., Theis, C. and Vincke, H., 2007, "Response of neutron detectors to high-energy mixed radiation fields", Radiation Protection Dosimetry, Vol. 125, No. 1-4, pp. 289-292.

Mitaroff, A. and Silari, M., 2002, "The CERN-EU High-Energy Reference Field (CERF) Facility for Dosimetry at Commercial Flight Altitudes and in Space", Radiation Protection Dosimetry, Vol. 102, No. 1, pp. 7-22.

Roberts, N.J., Jones, L.N., Králik, M., Park, H., Choi, K.O., Pereira, W.W., da Fonseca, E.S., Cassette, P., Dewey, M.S., Moiseev N.N. and Kharitonov, I.A., 2011, "International Key Comparison of
Measurements of Neutron Source Emission Rate (1999-2005): CCRI(III)-K9.AmBe", Metrologia, 48, Tech. Suppl., 06018.

Sato, T. and Niita, K., 2006, "Analytical Functions to Predict CosmicRay Neutron Spectra in the Atmosphere", Radiation Research, Vol. 166, pp. 544-555.

Schuhmacher, H., 2004, "Neutron Calibration Facilities", Radiation Protection Dosimetry, Vol. 110, No. 1-4, pp. 33-42.

Thermo-Scientific, 2009, FHT 762-WENDI-2 Datasheet. (n.42540/85 TD-E].

Wilson, J.W., Goldhagen, P., Maiden, D.L. and Tai, H., 1998, "High altitude radiations relevant to the high speed civil transport (HSCT)". NASA Technical Documentation, NASA.

Yasuda, H. and Yajima, K., 2010, "Characterization of Radiation Instruments at the Summit of Mt. Fuji", Radiation Measurements, Vol. 45, pp. 1600-1604. 